\title{
Puntos de mercado y formas de comercio en las costas atlánticas de la Lybie en época fenicio-púnica
}

\author{
Ports of Trade and Trade Strategies in the Atlantic Coasts of Lybie \\ in Phoenician-Punic Age
}

\author{
Fernando López PARDO \\ Publicado por primera vez en Fortunatae Insulae. Canarias y el Mediterráneo, \\ Santa Cruz de Tenerife, 2004, 85-100
}

\section{Primeros contactos y fundación de Lixus $^{1}$}

Durante la Prehistoria reciente los principales circuitos norteafricanos de intercambio de mercancías a larga distancia conectaban a las poblaciones saharianas con los grupos asentados en la costa Mediterránea y, en un recorrido transversal, a los grupos trashumantes de la franja costera del Magreb. El Marruecos atlántico se insertaba en estos circuitos incorporando su red de trueque intercontinental, basada en el flujo de armas desde la Península Ibérica a cambio fundamentalmente de marfil norteafricano destinado a fabricar objetos suntuarios. En este trasiego, las poblaciones de la región tangerina y el sur de Andalucía fueron durante la Edad del Bronce las detentadoras principales del intercambio, gracias a la cercanía que les procuraba el Estrecho de Gibraltar. Esta realidad traía aparejada un cierto trasvase cultural e ideológico que se manifiesta en el Bronce Tardío y Final especialmente a través de tradiciones funerarias comunes. A finales del segundo milenio y a principios del primero, la creciente llegada por mar de gentes del Mediterráneo oriental a la fachada atlántica peninsular y a la marroquí supuso un cambio cualitativo importante. Algo inédito es la entrada en contacto de formaciones sociopolíticas con diferente grado de desarrollo y complejidad social, que administraron y rentabilizaron las relaciones y los bienes que trocaron con fines muy distintos. Por otro lado, los estados mediterráneos a los que pertenecían los navegantes que se aventuraron por las aguas allende el Estrecho de Gibraltar propiciaron el paso de una situación de relaciones estrictamente marginales y esporádicas a otro marco diferente, más interactivo, fraguando una estructura de relaciones centro-periferia cuya incidencia mutua fue de índole infinitamente mayor a la habida en los contactos anteriores. Los marinos del mar interior acopiaron y contrastaron información sobre el Océano, sus costas, las gentes que las habitaban y sus

\footnotetext{
1 Este trabajo se ha desarrollado en el marco de los siguientes proyectos: "Mogador", I.P.H.E. e I.N.S.A.P; "Catálogo informatizado interactivo del patrimonio fenicio-púnico en Occidente para su publicación en la Web”, BHA 2002-02200, MCyT. He de agradecer también a L. A. Ruiz Cabrero sus siempre oportunas matizaciones sobre las etimologías fenicias aquí propuestas para ciertos topónimos.
} 
recursos y fueron forjando un imaginario atlántico que tuvo un impacto muy duradero en las mentalidades de griegos y fenicios, cuya nota más destacada era la imagen hostil de este mar, paulatinamente asociada a la idea de que atesoraba extraordinarias riquezas en ganados y metales. Riquezas más valoradas si cabe por la dificultad de acceder hasta ellas navegando en medio de múltiples peligros que sólo los más esforzados podían sortear siguiendo la supuesta estela dejada por sus dioses y héroes.

En ese proceso, la bahía de la embocadura del río Lucos debió ser punto de atraque repetido de naves del Mediterráneo oriental mucho antes de que se fundara un asentamiento permanente en el fondo de la bahía, Lixus. Vemos en el propio nombre de la colonia y del río que la acogió, $L k s ̌$, un significado estrechamente vinculado con los términos que se refieren a "los confines" (lqșm y lksm) en los textos ugaríticos del segundo milenio. Lqșm y lksm constituían el escenario mítico confinal al que llegaba su deidad solar, una deliciosa pradera costera próxima al mundo de los muertos. Este escenario se corresponde puntualmente con el Jardín de las Hespérides que algunas fuentes clásicas sitúan en Lixus. Según esta tradición, que creemos heredada del mundo fenicio, en dicho ámbito occidental también el sol abandonaba su carro y se instalaba en la copa que le llevaba placenteramente en su recorrido nocturno. Por lo tanto, la frecuentación de los levantinos de la Edad del Bronce, que seguramente ya codificaron el paisaje extremo-occidental, propició que al fundarse Lixus fuera elegido el nombre que la vieja categorización mítica le había atribuido antes al lugar. Se explicaría así coherentemente la tradición lixita que hacía del santuario de Melqart al lado del Jardín de las Hespérides, en el estuario del Lucos, el más antiguo del Extremo Occidente, anterior al de Melqart de Gadir. ${ }^{2}$

Hoy por hoy, Lixus parece ser el establecimiento fenicio más antiguo de la costa atlántica africana. La localidad ya tenía vocación urbana en el s. VIII a.C. cuando no antes, a fines del s. IX a.C., si extrapolamos a cronologías absolutas calibradas la datación de los materiales procedentes de los sondeos y excavaciones realizados en distintos lugares del hábitat, hallazgos que permiten cifrar la ocupación de ese momento en una extensión no inferior a las 12 ha. ${ }^{3} \mathrm{Su}$ considerable dimensión en época tan antigua permite incluir Lixus en el restringido grupo de ciudades fenicias de ese momento en el Extremo Occidente, un fenómeno urbano señalado por algunas fuentes ${ }^{4}$ que contrasta con el reducido tamaño de la mayoría de los enclaves fenicios de ese horizonte cronológico. ${ }^{5}$

Lixus fue desde esa época el gran centro regional de la fachada atlántica africana, atribuyéndosele una cierta equiparación con Gadir $^{6}$ y con Cartago como señala explí-

\footnotetext{
2 LÓPEZ PARDO 2007.

3 Habibi 1992; Aranegui - Belén - Fernández Miranda 1992, 10-11; López Pardo 1992, 87-89; ID. 2000a; Aranegui (ed.) 2001.

4 Cf. Str. I, 3, 2.

5 El análisis de las abundantes cerámicas a mano de las primeras unidades estratigráficas de los sondeos realizados en la colina de Tchemisch, tanto de las más groseras como de las bruñidas y esgrafiadas, permite asegurar que el proyecto urbano fenicio de la extensa colina se realizó integrando población autóctona e indígenas traídos del sur de la Península, quizás de la costa oriental de Andalucía y seguramente en régimen de dependencia (LóPEZ PARdo - SuÁREZ 2002, 118-123).

6 Str. XVII, 3, 2.
} 
citamente Plinio refiriéndose a una época pasada. ${ }^{7}$ Además del prestigioso y antiguo santuario de Melqart que se encontraba en una isla del estuario, la ciudad contaba intramuros con un recinto cultual de grandes dimensiones a juzgar por los vestigios sacros de época mauritana y romana hallados en la plataforma inferior de la colina. De debajo de uno de los templos procede un ánfora R1 arcaica con un graffiti de contenido cultual $\mathrm{y}$ un pie de figura de terracota de presunto uso sacro, hallados entre un conjunto muy homogéneo de materiales de la segunda mitad del s. VIII - inicios del VII a.C., lo cual permite asegurar que la plataforma de los templos ya fue definida como un espacio de uso sacro desde época fenicia arcaica. ${ }^{8}$

La datación alta de la fundación, sus dimensiones y las excelentes condiciones portuarias del fondeadero del Lucos permiten asegurar que la prosperidad ciudadana se debía en buena medida a su carácter de gran centro redistribuidor comercial en el que también se realizaban diferentes actividades productivas y artesanas, remedándose así el modelo metropolitano de Tiro que se puede apreciar también en la colonia de Castillo de $\mathrm{D}^{\mathrm{a}}$ Blanca en la bahía de Cádiz, identificada con la propia Gadir. ${ }^{9}$ Las explotaciones agrícolas y ganaderas debían encontrarse en las tierras que se extienden al norte de la ciudad, donde se constata un intenso aprovechamiento de recursos abióticos desde el final de la Prehistoria, ${ }^{10}$ lo cual tiene su reflejo en el consumo local de cereales, leguminosas y carne de bovino y ovicápridos. No menos importante para la dieta de los lixitas era el consumo de pescados de mediano tamaño procedentes del mar circundante como ha quedado bien documentado a través de las últimas excavaciones. ${ }^{11}$

Como ya hemos señalado, las condiciones portuarias del golfo estuarino del Lucos eran excelentes y la ciudad contaba además con un embarcadero protegido por la propia colina del asentamiento, cuyas estructuras romanas son aún visibles. Ello convirtió el puerto en refugio y punto de partida para los barcos que se aventuraban en la navegación hacia el sur, fue así un lugar de memoria donde se debían conservar informaciones útiles de anteriores travesías. De alguna manera es reflejo de este papel el que Hannón, según su conocido periplo, llevara en sus naves a algunos lixitas con el fin de que le sirvieran de intérpretes y que, a la postre, fueran los que iban indicando los nombres de los parajes que visitaban. A su vez, la llanura por donde discurre el cauce del Lucos, navegable en un trecho, permitía una rápida penetración hacia el interior del país, hasta las primeras estribaciones del Rif y del Atlas, y daba acceso a la planicie del Gharb por donde discurren grandes uadis como el Sebú y el Beth. No obstante, hasta el momento sólo se ha podido obtener testimonio arqueológico de la proyección lixita sobre dicho hinterland a partir del s. VI a.C. Recientemente se ha localizado en el curso del río Lucos, a $24 \mathrm{~km}$ de Lixus, un hábitat autóctono de dos hectáreas en la colina amesetada de Azib Slaoui donde se ha recogido vajilla de engobe rojo y abundantes ánforas de presumible origen lixita. ${ }^{12}$

7 Plin. Nat. Hist. V, 2, 4.

8 LÓPEZ PARDO 2005.

9 Ruiz Mata 1999.

10 Ponsich 1966.

11 Aranegui (ed.) 2001.

12 Akerraz - El Khayari 2000. 


\section{La época de las fundaciones agregadas}

Es necesario descender a un segundo momento cronológico para descubrir nuevas fundaciones en la costa atlántica africana. Para evocarlas vamos a trazar un recorrido tomando como vértice el cabo Espartel, realizando un periplo imaginario hacia el sur hasta llegar a la isla de Mogador, la mítica Kérnē, donde se encontraba la última factoría fenicia que conocemos en la costa africana.

Con renovado interés vemos hoy la información reportada por el Periplo de Hannón ${ }^{13}$ sobre los nombres de los enclaves coloniales que supuestamente fundó el cartaginés una vez que levaron anclas en una laguna próxima al cabo Spartel y antes de llegar al gran río Lixos (Lucos). Aunque hoy en día no estamos en disposición de confirmar el carácter hannoniano de las fundaciones, pues pueden ser anteriores y deberse a una dinámica de ocupación generada en la misma zona, la revisión reciente de los topónimos permite asegurar su origen genuinamente fenicio-púnico, menos alterados por la edición griega del periplo de lo que se pensaba hasta ahora. Los enclaves mencionados en el Periplo son Karikon Teichos, Gutte, Akra, Melitta y Arambys y los ordenaremos de norte a sur según los indicios con los que contamos para su ubicación, entendiendo que el Periplo los presenta desordenados.

Parece altamente probable que Arambys se encontrara muy próxima al cabo Spartel, pues este último es denominado Arampe en un portulano griego del siglo XVI. El yebel Kebir, que da forma orográfica al cabo Spartel, y la localidad mencionada en el Periplo de Hannón debían llamarse en lengua fenicia har anbin "monte de las uvas" como se viene sosteniendo. ${ }^{14}$ Es segura la validez de la ubicación y la reconstrucción del nombre semita y su significado en relación con las uvas ya que los griegos conocían el cabo Spartel como Ampelusia, "de las viñas". ${ }^{15}$ Pomponio Mela, ${ }^{16}$ que era natural de la región, nos lo confirma al señalar que si bien los griegos lo llaman Ampelusia, los africanos en su lengua llamaban con el mismo significado, por lo que habría que entender que las gentes del país, púnicoparlantes, lo designarían precisamente har anbin. ${ }^{17}$

Próxima a Arambys o al "monte de las uvas" podría encontrarse Guttē, si tenemos en cuenta que en fenicio *Gitt significa "prensa de vino" según E. Lipinski, ${ }^{18}$ pareciendo existir una relación funcional o simbólica entre ambos topónimos. ${ }^{19}$ Deberíamos identificar quizás Arambys y/o Guttē con los restos arqueológicos próximos al fondeadero del cabo Achakar y de la colina de Djebila. En esta última se han hallado ánforas fenicias y púnicas ${ }^{20} \mathrm{y}$ al pie de la colina aparecieron unos fragmentos de cerá-

13 Hano 5.

14 Carcopino 1948; Rebuffat 1976, 143.

15 Plin. Nat. Hist. V, 2.

16 Mel. I, 5.

17 Rebuffat 1976, 146.

18 LIPINSKI 1992a.

19 Aunque la relación no es segura pues puede tener un significado más amplio, como explotación agrícola o hacienda. Cf. gt en ugarítico y gittu en acadio de Tell el Amarna, donde además de trujal o lagar tiene el sentido de alquería, Olmo Lete 1996, 152.

20 Ponsich 1964, 266. 
mica griega, entre ellas una crátera laconia del s. VI a.C. y una copa ática de figuras negras del 500-490 a.C. ${ }^{21}$ En relación con el poblamiento de esta zona se hallan tanto la necrópolis de tradición indígena con influencia púnica aledaña al hábitat de Djebila y la más alejada necrópolis de cámaras del Ras Achakar. ${ }^{22}$

Algo más al sur se encuentra la desembocadura del río Tahadart, el cual conserva en la actualidad una extensa planicie inundada en algunas épocas del año, vestigio de un antiguo gran lago, abierto al mar según los resultados de los sondeos paleambientales realizados. ${ }^{23}$ Este amplio estuario abierto a la influencia marina debía ser el que Mela ${ }^{24}$ llama Gna y Ptolomeo ${ }^{25}$ Agna, situado según el primero entre la colonia (Zilis) y el cabo Ampelusia. De nuevo la denominación nos parece de origen feniciopúnico, pues se constata epigráficamente 'gn referido a recipientes para contener líquidos, ${ }^{26}$ y en ugarítico agn se usa como en otras lenguas semíticas para "estanque" "cubeta". ${ }^{27}$ Estas últimas acepciones serían las que cabría atribuir para la denominación fenicio-púnica del golfo del Tahadart, ${ }^{28}$ en cuyos bordes se debían disponer distintas fundaciones fenicio-púnicas.

Volviendo de nuevo a las localidades mencionadas en el Periplo de Hannón, pero sin salir seguramente de esta formación estuaria del 'gn/Tahadart, hemos de mencionar Karikon Teichos, que ya en solitario A. Blázquez y Delgado-Aguilera ${ }^{29}$ relacionara con el lugar moderno de Xeraka, precisamente en el fondo norte de este antiguo lago. La aproximación adquiere mayor verosimilitud desde el momento en que podemos situar los otros enclaves mencionados por el Periplo en este contexto espacial y por la nueva lectura que realizamos del topónimo. ${ }^{30}$ Los griegos ya desde el siglo IV a.C. al menos habían dado a Karikon Teichos el sentido de "fuerte cario" 31 y así se mantiene en el manuscrito griego del Periplo de Hannón, pero nosotros entendemos que se trata de una simple interpretatio graeca, pues teichos (fuerte, fortificación) es una traducción en griego de $k r k$, término ampliamente documentado en lenguas semíticas con el mismo sentido de fortificación, recinto fortificado, ciudad fortificada, ${ }^{32}$ con lo que el auténtico nombre de la localidad fenicio-púnica era éste, $k r k$.

El golfo encontraba su límite sur en el promontorio de Ras al Kuass que lo separa de la desembocadura del propio río Kuass. Precisamente en una terraza de este saliente se encuentran las ruinas excavadas de un hábitat prerromano con restos arqueológicos bien datados en pleno s. VI a.C. pero con posibilidades de que algunos sean

21 Villard 1960, 12-14; Ponsich 1970, 185.

22 PONSICH 1967.

23 Ballouche 1986, 63.

24 Mel. III, 10.

25 Ptol. IV, 2.

26 Krahmalkov 2000, 31

27 Cf. Olmo Lete 1996, 13; Cohen 1999, 7.

28 Quizás también sea el río Anides mencionado por el Pseudo Escílax (112) que se encuentra entre el cabo Hermeo y el Lixos, que desemboca en un gran lago.

29 Blázquez y Delgado-Aguilera 1921, 415.

30 López PARdo - Mederos - Ruiz Cabrero 2006. De forma independiente ha llegado a una conclusión similar FANTAR (2002) al relacionar Karikon con $Q r$, que tiene un significado parecido.

31 Eforo, Fr. Gr. Hist. 70, 53.

32 Cf. HoftiJzer - Jongeling 1995, 535-536; Krahmalkov 2000, 241. 
incluso anteriores. El enclave fenicio llegó a contar después con un destacado centro alfarero dedicado especialmente a la manufactura de ánforas ${ }^{33}$ destinadas fundamentalmente al envasado de salazones de pescado. ${ }^{34}$ Sus talleres cerámicos también abastecían de vasos de uso funerario a las poblaciones indígenas asentadas en la región tangerina ${ }^{35}$ que en parte se seguían enterrando con rituales propios de la tradición de la Edad del Bronce. De entre los nombres recogidos por el Periplo de Hannón podríamos atribuir a este asentamiento del Ras al Kuass el de Akra, pues es traducción del fenicio $R s$ (cabo, promontorio).

Completa el panorama de fundaciones trazado en el Periplo de Hannón, antes de que las naves del cartaginés llegaran al puerto de Lixus, el asentamiento mencionado en el documento con el nombre de Melitta, quizás una confusión o asimilación intencionada entre Melitta $<$ Selitta que debería identificarse con la localidad reconocida por acuñaciones monetales de 'šlyt, topónimo púnico que significaría "Red" o "Pesquería". ${ }^{36}$ Aunque 'šlyt se ha identificado frecuentemente con Zilil, parece altamente improbable pues no presenta concomitancias fonéticas claras. Sería posible sugerir Asilah (Arcila), que se encuentra unos kilómetros más al sur sobre la costa, la cual habría conservado el topónimo antiguo.

\section{El golfo empórico (Kolpos emporikos)}

Según una información recogida por Estrabón ${ }^{37}$ y seguramente transmitida antes por Ofelas y Eratóstenes, en estos lugares se encontraba un golfo llamado "empórico" que albergaba establecimientos comerciales fenicios. Aunque frecuentemente se ha imaginado al sur del Lucos, algunos indicios hacen sospechar que las antiguas fuentes de Estrabón se estaban refiriendo a la costa comprendida entre el cabo Spartel y el estuario del Lucos inclusive. Aunque el autor señala explícitamente que se encuentra al sur de Lixos y los Koteis, también es cierto que Lixos, como señala unas líneas antes Estrabón, había sido confundida por Eratóstenes con Tinx (Tánger), que se encuentra precisamente en las proximidades de los Koteis (otro nombre del cabo Spartel). Es evidente que el geógrafo al tomar la noticia de Eratóstenes nos ha reportado la referencia geográfica equivocada, pues es coherente la mención a los Koteis y Tinx (confundida con Lixos) por su cercanía para situar con precisión el golfo, pero hubiera sido superfluo y confuso mencionar los Koteis si realmente se encontrara dicho golfo al sur del Lucos. Nos lo confirma el propio Estrabón cuando dice que en el Kolpos emporikos se encuentra un antro con un terreno bajo y unido donde se eleva un

\footnotetext{
33 PONSICH 1968.

34 López PARDo 1990, 23. Una revisión a fondo de las antiguas excavaciones y un estudio sistemático de los materiales de Kuass han sido realizados por Mohamed Kbiri Alaoui en su tesis doctoral que saldrá publicada próximamente.

35 Kbiri Alaoui 2000.

36 Mazard 1955; Le Glay 1992, 127.

37 Str. XVII, 3, 2.
} 
altar de Heracles, que jamás recubre el flujo, ${ }^{38}$ escenario al que alude Plinio situándolo en el estuario del Lucos. ${ }^{39}$

Así pues, la franja costera que incluía las formaciones estuarinas del Tahadart y de Lixus se configura como ámbito de actividades empóricas, de comercio intenso para los fenicios y posiblemente para los griegos en las fechas de la arcaica fuente de Estrabón (s. V a.C.?). Quizás la denominación, procedente seguramente del Periplo de Ofelas, fuera acuñada por mercaderes griegos que tenían designados estos puertos para sus transacciones en la costa atlántica africana. El texto subraya que los enclaves eran mantenidos por los fenicios, cuya actividad debía centrarse en el intercambio con los indígenas, generando un acopio de materias a las que podían acceder distintas entidades comerciales griegas, de ahí el interés de calificar este golfo como emporikos (comercial).

En este contexto, Lixus seguramente contaba con el emporion designado más importante de la región a juzgar por la dimensión urbana de la localidad y por el conocimiento que presenta la vieja fuente griega sobre el estuario del Lucos. Quizás, la ciudad tenía reservado un espacio "externo" dedicado a dichas transacciones con aquellos emporoi extranjeros que tenían concedido el derecho de acceso al puerto, mercaderes que se encontraban así bajo el amparo de leyes y reglamentos y bajo el control de magistrados. ${ }^{40}$ Kuass podría ser otro de estos emporia pues se han hallado ánforas de salazones fabricadas en esta localidad en un almacén del ágora de Corinto ${ }^{41} \mathrm{y}$ ánforas de este mismo tipo pero sin origen definido se han recuperado en la propia Atenas. Por su parte, en Kuass se ha recuperado cerámica ática en abundancia junto a un variado registro de ánforas procedentes del ámbito del Estrecho y del Mediterráneo central, lo cual le permite a M. Kbiri Alaoui ${ }^{42}$ señalar que se trata de un centro redistribuidor en el que la presencia de cerámica de Atenas está íntimamente relacionada con el circuito que vehiculaba hacia Grecia los productos derivados de la pesca preparados en Kuass.

\section{Al sur de Lixus}

En ese momento antiguo al que se refiere Estrabón (s. V a.C.?), aparentemente los griegos no podían ir más al sur para cerrar transacciones comerciales, no porque los numerosos establecimientos tirios que se encontraban más allá de este golfo son llamados coloniales en vez de distinguirlos como factorías, sino porque se hallaban abandonados al haber sido destruidos por poblaciones indígenas especialmente belicosas, los Pharusii y Nigrites. ${ }^{43}$ No es posible, por el momento, comprobar si es exagerada la noticia sobre el número de asentamientos, ni, en su caso, averiguar el

38 Str. XVII, 3, 3.

39 Plin. Nat. Hist. V, 2-4.

40 Cf. Bresson 1993, 165.

41 Maniatis et alLII 1985.

42 KBiri Alaoui 2003.

43 Str. XVII, 3, 3 y 8. 
alcance de las destrucciones, pero el hecho es que existe un rastro evidente de presencia fenicio-púnica estable más allá del Lucos.

El tránsito naval frecuente entre Lixus y la desembocadura del Sebú permitió sin duda codificar uno de los promontorios de esta línea costera con el nombre de Melqart (Rs Mlqrt), nombre conservado en un portulano de origen medieval que cita el Rasmikar. ${ }^{44}$ Encontramos una confirmación en Ptolomeo ${ }^{45}$ que sitúa en estas latitudes el Promontorio de Herakles, el héroe griego con el que habitualmente se asimila al dios fenicio. Un primer abrigo portuario se encontraba en Moulay Bouselham que da acceso a una zona de marjal que antiguamente sirvió para el atraque de barcos. Este lugar era conocido en los portulanos medievales con el nombre de Mosmar, Mismar, etc., pero su etimología es desconocida en árabe lo que hace sospechar que fuera de origen púnico. ${ }^{46} \mathrm{Ms} m r$ es en fenicio "abrigo", "lugar protegido", ${ }^{47}$ lo que se adecua a las excelentes condiciones de refugio para los barcos que ofrece la "laguna azul" (Merja Zerga).

El uadi Sebou, la gran vía natural de penetración de la llanura del Gharb, era transitado por las naves fenicias que recorrían sus sinuosos meandros hasta Banasa, a 80 $\mathrm{km}$ de la desembocadura. El nombre antiguo del río, Sububus según Plinio, ${ }^{48}$ creemos que procede de la voz fenicia $s b b$ "dar vueltas", "girar" ${ }^{49}$ muy apropiado para aludir a los inmensos meandros que describe el río hasta su curso medio. Cerca del estuario se encuentra Thamusida, localidad de importante florecimiento en época mauritana ${ }^{50}$ que parece arrojar evidencias de una ocupación fenicia arcaica. Esta cuenca fluvial, seguramente de gran interés económico para los fenicios, contaba con un asentamiento a término para las naves en Banasa, donde algunos sondeos arqueológicos sacaron a la luz algunos alfares en los que se manufacturaron cerámicas de tradición local y se imitaron formas importadas que llegaron con fluidez al enclave. Se pueden datar sus orígenes en una fecha anterior a mediados del s. VI a.C. pues se han hallado algunas ánforas fenicias Rachgoun 1 y una lucerna ática del tipo Howland $23 \mathrm{~A} .{ }^{51}$ Seguramente en conexión con Banasa y la vía de penetración del Sebú se encuentra el hallazgo de un ánfora Mañá-Pascual A4 datable del s. III a.C. en el túmulo principesco de Sidi Slimane, sobre el uadi Beth ${ }^{52}$ cuya cámara funeraria estaba cubierta con vigas de thuya, bella madera imputrescible y olorosa altamente apreciada en el arreglo suntuario de palacios y templos de la época.

El siguiente cauce fluvial de cierta envergadura es el Bou Regreb, en cuya desembocadura se encontraba Sala o Salat. ${ }^{53}$ Su nombre fenicio, $S^{\prime}$ lt/Salat, es una forma

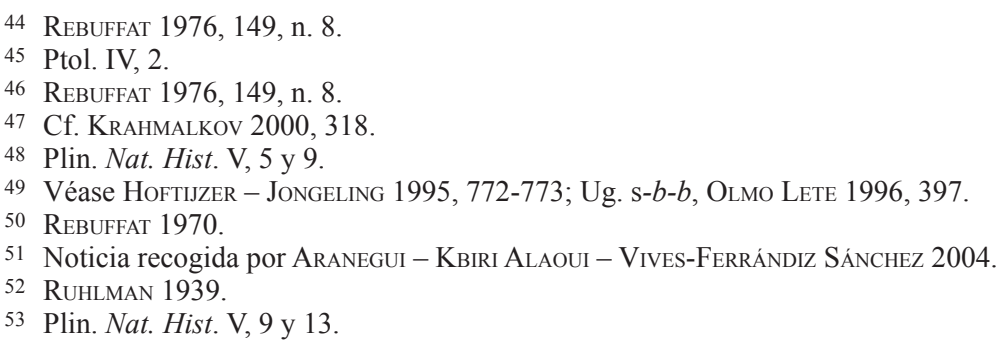


femenina de *Sl y corresponde al significado de "peñasco". ${ }^{54}$ Quizás el nombre se refiere al saliente berroqueño de la Casbah de los Oudaias (Rabat), en el mismo estuario, donde se encontraron cerámicas fenicias o púnicas. ${ }^{55}$ No obstante, los restos de la ciudad púnico-mauritana y después romana, se encuentran en la siguiente curva del río, en el recinto de la necrópolis meriní de Chellah (Šella), que parece haber conservado el nombre antiguo, ${ }^{56}$ donde se hallaron algunos fragmentos de cerámica de engobe rojo quizá arcaica. ${ }^{57}$

Desde la desembocadura del Bou Regreb hasta el cabo Ghir, allí donde el Atlas se asoma al mar, la costa es poco hospitalaria y apenas ofrece abrigos naturales para la navegación. Sólo las desembocaduras de los ríos siguen siendo refugio seguro cuando la barra no hace impracticable el paso de entrada. ${ }^{58}$ Precisamente los periplos antiguos se vuelven especialmente oscuros y escasos de información al describirnos este tramo, y a pesar de ser una zona repetidamente prospectada, poco es lo que se ha señalado como prerromano..$^{59}$ En Azenmour, junto a la desembocadura del Oumm er Rebia, P. Cintas señaló el hallazgo de fragmentos de cerámica púnica. ${ }^{60}$

\section{Mogador, una factoría estacional}

El viajero medieval El-Bekri ${ }^{61}$ ya señaló que Mogdoul (actual Essaouira) era un fondeadero muy seguro, sin duda gracias a la protección contra el oleaje que le brindaba la isla de Mogador y el saliente rocoso donde se asienta la localidad actual. Un asentamiento fenicio surgió en la isla en la primera mitad del siglo VII a.C. subsistiendo algo más de cien años; este se localiza en la costa oriental, la que da al continente y la más resguardada de los fuertes vientos que soplan del noroeste. La ausencia de muros entre los vestigios fenicios ya hizo sospechar a A. Jodin ${ }^{62}$ que se trataba de una factoría estacional, aspecto que puede confirmarse a través de la cultura material exhumada. La falta de talleres alfareros, propia de un asentamiento temporal, hizo que los residentes repararan con frecuencia los platos y cuencos rotos y, ante la imposibilidad de adquirir o reparar las lámparas de aceite, las reproducían rudimentariamente. También es significativa a este respecto la profusión de graffiti grabados en la vajilla de mesa y las ánforas, según veremos más adelante.

Distintos indicios denotan que un alto porcentaje de los recipientes cerámicos hallados en Mogador procedía de un mismo taller foráneo. ${ }^{63}$ Sería sugerente pensar en Castillo de Da Blanca, que tantos paralelos nos ha aportado, para proponer Gadir

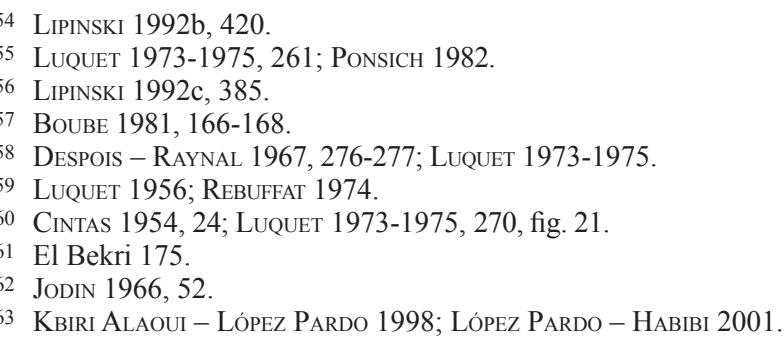


como el lugar de procedencia de estos productos. Sin embargo es también sugestiva la idea de que alguna factoría permanente situada en la costa atlántica africana, en la desembocadura del Bou Regreb, o del Oum er Rebia, etc., fuera la que se ocupó del envío estacional de personas y mercancías a la isla. Queda sin embargo patente, si este fuera el caso, que el enclave que provee a Mogador recibe unos amplios estímulos de Gadir, aunque no son desdeñables las similitudes con los productos de la Axarquía malagueña. Por otra parte, el papel desempeñado por Lixus en la provisión de productos a la factoría pudo ser destacado, pero hoy por hoy no puede ser explicitado pues apenas se conocen materiales lixitas de los siglos VII y VI a.C.

Sin embargo, las ánforas fenicias occidentales (R1) halladas en el yacimiento presentan una variedad de pastas y engobes realmente remarcable que denotan una gran diversidad de procedencias, entre ellas hemos podido identificar algunas originarias de la costa malagueña, de la bahía de Cádiz y de Lixus, lo que denota que en el abastecimiento de vino, aceite y conservas Mogador dependía de un centro redistribuidor del ámbito del Estrecho que también se ocupaba de hacerle llegar vino y aceite de Grecia y de Chipre.

La cultura material de la factoría, tan repetida en el ámbito fenicio occidental, oculta, sin embargo, una cierta diversidad en el origen de los individuos desplazados allí, como puede apreciarse por los nombres leídos sobre todo en los fondos de los platos y cuencos de engobe rojo. Junto a una mayoría de fenicios aparece un sujeto de nombre moabita, uno hebreo y otros nombres cuyo origen no se ha podido determinar. ${ }^{64}$ Las personas que se desplazaban a la isla marcaban con una letra o su nombre algunos de sus enseres para que no fueran trastocados, una práctica claramente vinculada al mundo marinero y mercantil, lo que explica su alto número en Mogador.

La parte conocida de la factoría fue abandonada a mediados del s. VI a.C. y no sabemos si ello significa que la ensenada dejó de frecuentarse con la intensidad que lo había sido hasta ese momento o que el lugar de residencia se desplazó a otro punto en la propia isla o en el continente. El hecho es que la estratigrafía del yacimiento muestra antes de la intensa ocupación de época de Juba II algunos restos de ánforas de la región del Estrecho fechables entre los siglos V y III a.C. y huesos de elefante que indican una actividad humana de carácter esporádico o marginal en este sector tras su abandono. ${ }^{65}$

\section{Mgdl Qrnm}

La localidad de Mogador, actual Essaouira, (enfrente de la isla) era conocida en textos árabes del siglo XI con el nombre de Amogdoul y precisamente junto a la desembocadura del río Ksob, frente a la isla, se encuentra el morabito de un santón musulmán que recibe el nombre de Sidi Mogdoul. Como recoge Stumme, ${ }^{66}$ mogdul es un término que aparece en fenicio y púnico con el significado de "torre", documentado

64 Sobre tales antropónimos véase AmadASi GuZzo 1992, 173. Se incorporan nuevos graffiti y se analizan las formas cerámicas en que aparecen en: RuIZ CABRERO - López PARDo 1996.

65 Jodin 1957; López PARdo 2001, 228.

66 Stumme 1912, 123-124. 
desde el segundo milenio a.C. ${ }^{67}$ Con el tiempo Mogdoul se transformó en Mogdura para los portugueses y en Mogadur para los españoles. ${ }^{68}$

Por su parte, el Anónimo de Rávena recoge de fuentes romanas del Alto Imperio el nombre de la estación denominada Turris Buconis. Ptolomeo ${ }^{69}$ sabe del mismo enclave y lo transcribe en griego como Boccanon Hemeroscopeion (atalaya), casi al final de una ruta caravanera jalonada por unos pocos puestos que comunicaba Volubilis con el valle del Sous y la costa, precisamente en las inmediaciones de Mogador. Sin duda turris y hemeroscopeion son el trasunto del púnico magdal/mogdul, nombre con el que se conocía en época prerromana el lugar.

La denominación latina nos permite considerar que el nombre púnico era $M g d l$ qrnm, es decir "Torre de los (dos) cuernos", o bien Mgdl qrn "Torre de la cornamenta", en cualquiera de las cuales está implícita la referencia a la isla por su semejanza con una gran cornamenta como hemos podido comprobar sobre el terreno y a través de la cartografía. No es posible por el momento imaginar la existencia de una torre o hábitat fortificado en relación con la factoría estacional arcaica, pues no ha aparecido ninguna estructura construida en el área excavada, aunque nada impide que fuera de este sector se encontrara una obra de estas características. Sea cual sea el momento de construcción de la fortificación, época fenicia arcaica o púnica, lo que nos parece más destacable es que el segundo componente del nombre, Buconis/Buceron, traduce Kérne "cornamenta" en lenguas semitas y que aún bajo la romanidad los pobladores de raigambre púnica de la zona seguían comprendiendo su significado primigenio.

\section{Producción e intercambios en el área de Kérnē/Mogador}

La isla de Kérnē, que así definitivamente identificamos con Mogador, ${ }^{70}$ nos era conocida a través de textos griegos desde el s. IV a.C. y hace alusión a un tópos geográfico de los más sugerentes de la Antigüedad: confín suroccidental del mundo conocido, donde los fenicios realizaban transacciones comerciales con altos etíopes que se encontraban en estrecho contacto con los dioses. ${ }^{71}$

La conclusión es del mayor interés pues permite aunar la información arqueológica de Mogador y la textual sobre Kérnēe, ricas ambas en datos sobre actividades económicas que giraban en torno al intercambio de bienes. Uno de los datos desvelados recientemente de las antiguas excavaciones es la constatación de actividad

67 Olmo Lete 1981, 574. El topónimo lo encontramos en el sur de Fenicia y correspondería al nombre de diferentes plazas fuertes o torres fortificadas (Ejem.: Migdal El (Jos. 19 37-39), Migdol (Ez. 14, 1-2).

68 LIPINSKI 1992, 126; ID. 2000, 285.

69 Ptol. IV, 7.

70 Si bien la localización de la isla de Kérnē ha sido objeto de debate durante muchos años, proponiéndose como candidatas casi todas las islas de la costa atlántica africana, los trabajos arqueológicos de Jodin en Mogador (JodIN 1966) y el análisis de los textos realizado por EuZENNAT (1994) ya habían hecho prevalecer la hipótesis de que Kérnē era Mogador.

71 Ps. Scyl. 112. 
siderúrgica en la factoría, gracias al hallazgo de abundantes escorias de fundición, ${ }^{72}$ toberas y fragmentos de hornos o moldes de barro para los lingotes. El mineral procedía del entorno, pues a unos $25 \mathrm{~km}$ al nordeste de la isla existen concentraciones férricas en el Yébel Hadid (montaña del Hierro, en árabe) que han sido explotadas en época reciente. También precisamente a la altura del monte sobresale en el mar el Ras Hadid (Cabo del Hierro). Esta actividad metalúrgica en la isla indica que el enclave norteafricano parece reproducir la misma estrategia productiva y comercial que otros asentamientos fenicios occidentales donde se han localizado hornos de fundición. Su objetivo era el abastecimiento de las tribus del entorno, las cuales no habían incorporado o desarrollado aún la tecnología del hierro, igual que sucedía con la mayoría de las comunidades indígenas del Extremo Occidente en esa época. Esta producción constituía un instrumento sumamente eficaz para potenciar los intercambios y hacer llegar a la factoría los productos tradicionalmente obtenidos en el país: marfil, pieles, huevos de avestruz, oro, etc. ${ }^{73}$

El sur de Marruecos apenas ha reportado objetos metálicos prerromanos, por lo que seguramente eran extraordinariamente escasos y la mayoría debía proceder del comercio exterior y de factorías como Mogador, aunque ello no es obstáculo para sospechar que hubiera alguna producción local, especialmente de armas de cobre y bronce. ${ }^{74} \mathrm{~A}$ este respecto es necesario destacar que el armamento de hierro proporcionaba un formidable poder de coerción a los grupos que podían acceder a él, frente a aquellos otros que contaban con armamento lítico, de cobre o de bronce, en el mejor de los casos. ${ }^{75}$ Parece innegable que este mayor aporte desde la factoría de Mogador de armas metálicas técnicamente más sofisticadas tuvo una considerable incidencia desestabilizadora en la región atlásica y llevó a la reestructuración de las redes de intercambio en beneficio de Mogador/Kérnē como nuevo foco de atracción de las materias primas regionales de interés colonial. La ensenada de Mogador se convirtió forzosamente en el fin del viaje de grupos ganaderos y de buhoneros que intercambiaban en verano sus preciados bienes con los comerciantes/metalúrgicos semitas.

La isla de Mogador/Kérnē trasciende en el mundo mediterráneo como ejemplo de lugar de intercambios. El periplo del Pseudo Escílax ${ }^{76}$ imagina las relaciones comerciales entre los etíopes del entorno de Kérnē y los fenicios con un esquema claramente empórico, donde la isla figura como el ámbito asignado para la residencia temporal y almacén de los emporoi fenicios que llegan en sus gauloi (barcos redondos). Las transacciones

72 A. Jodin recientemente ha señalado que en sus excavaciones de 1956 y 1957 apareció abundante escoria de hierro en los niveles fenicios (ARANegui - Gómez Bellard - Jodin 2000, 35). Entre los materiales de Mogador de los depósitos del Museo Arqueológico de Rabat se encuentran dos toberas de arcilla vitrificadas por la acción del calor, pero antes de la noticia de A. Jodin sobre las escorias hicimos poco caso en razón de su posible uso para la reparación de objetos metálicos, como se había apuntado para otros yacimientos como Morro de Mezquitilla y Toscanos. Los fragmentos de hornos o moldes los hemos encontrado también en los depósitos del museo y en el yacimiento.

73 LÓPEZ PARdo 2000, 37-38.

74 Las alabardas representadas en las estaciones rupestres de Oukaimeden, cerca de Marrakech, y del Yagour (SimONEAu 1968-1972, 18; Jodin 1964) tienen su paralelo estricto en las armas del Sudoeste de la Península Ibérica de la Edad del Bronce.

75 Cf. Vernet 1996.

76 Ps. Scyl. 112. 
con los etíopes se cumplimentaban en el continente, a donde llegaban desde la isla en pequeñas embarcaciones.

Algunos datos parecen coherentes con la latitud donde se realizan las transacciones. En el texto se caracteriza a estos etíopes, como no podía ser de otra manera, como cazadores y pastores, comedores de carne, bebedores de leche, que usan el marfil de los elefantes cazados para sus copas y ornamentos. Las mercancías que ofrecen a los emporoi fenicios son congruentes con el panorama etnográfico trazado en el Periplo: pieles de gacelas, de leones y leopardos, de animales domésticos, pieles y defensas de elefantes. Sin embargo, a continuación se hace una afirmación que no corresponde a ese modo de vida, "producen mucho vino de sus viñas", hasta el punto que los mercaderes fenicios se llevan consigo una parte. En vez de discutir la posibilidad de que en estos parajes fuera posible o no el cultivo de la vid, intentando así dar por válida o no la afirmación del Periplo, hemos de fijarnos precisamente en los bienes que son transferidos por los semitas a estos etíopes que son calificados como "sagrados" en el texto. Creemos que la enumeración está estrechamente vinculada con la cultura del vino, así, aparte de perfumes y aprous exaraktous (expresión incomprensible), los fenicios les reportan cerámica ática, en la que puede aludirse precisamente a cráteras, ánforas y copas, los recipientes áticos para contener vino, los más frecuentes en contextos no griegos. También el texto especifica las choes, las jarras de vino que se utilizaban en el festival dionisíaco de las Choes de Atenas como señala el propio autor. ${ }^{77}$ Las "piedras de Egipto", a las que no se ha dado una explicación convincente, serían a la luz de este texto los reputados envases egipcios de alabastro para contener vino que los fenicios comercializaban, artículos de lujo que distribuían con profusión incluso en la Península Ibérica.

Creemos que el objetivo de esta enumeración de recipientes no parece ser sólo poner de relieve la sorprendente producción etiópica de vino, sino muy especialmente destacar que este lo consumían los etíopes ieroi (sagrados) al modo que había sido establecido por Dionisos. La coherencia mitológica vendría dada por una tradición, que sin duda conocía el Pseudo Escílax, según la cual Dionisos habría nacido en la parte occidental de Libia, cerca de los montes Keraunioi ${ }^{78}$ topónimo que presenta una simbiosis fonética y de significado con Kérnē. De esta manera, el dios, maestro de la vinificación para los humanos, habría enseñado a los etíopes esta técnica en su infancia, siendo así los primeros, o en caso contrario, el dios sería aprendiz aventajado de estos primigenios viticultores.

La consistencia de la tradición del nacimiento de Dionisos en estos parajes del Extremo Occidente, con gestación llevada a término en el muslo de Zeus, procede de unos pasajes homéricos que nos recuerdan la estancia de este dios acompañado de los demás Inmortales entre los etíopes: "Zeus fue ayer al Océano a reunirse con los intachables etíopes para un banquete, y todos los dioses han ido en su compañía. Al duodécimo día regresará al Olimpo". ${ }^{79}$ Se insiste en el asunto en otro pasaje donde

77 Efectivamente, los habitantes del Ática conmemoraban la llegada de Dionisos a Aiora con dicha fiesta del vino nuevo, en la que tenían un papel destacado las choes (HAMiLTon 1992, 69-70).

78 Diod. III, 68, 2; Desanges 1978, 117.

79 Hom. Il. I, 423-425. 
se señala que Iris no tiene tiempo de tomar asiento pues desea volver al Océano, a la tierra de los etíopes, para participar del sacro festín que están ofreciendo a los dioses. ${ }^{80} \mathrm{El}$ paraje donde se celebra el convite es naturalmente el de los confines, pues en ellos, en el poniente y la aurora, habitan los etíopes que disponen los banquetes para los Inmortales. ${ }^{81}$

Por lógica, los etíopes debían contar no sólo con la carne que les proporcionan animales salvajes y domésticos, sino también con el mejor vino, procedente de sus viñas, para los ilustres convidados que esperan. En esta tesitura la epifanía de Dionisos en el Extremo Occidente adquiere coherencia no sólo por las regulares visitas de Zeus, sino también por la necesidad de explicar la inusitada producción de vino etiópica, imprescindible en unos festines en los que participan los dioses.

Precisamente creemos que la contrapartida que reciben los fenicios mencionados por el Pseudo Escílax a cambio de los utensilios necesarios para los festines procede de los preparativos de los banquetes, pues lo que obtienen son pieles de animales salvajes y domésticos, en las que debemos ver fundamentalmente los despojos de las víctimas sacrificadas. También la adquisición de marfil señalada en el Periplo es resultado de la caza de elefantes por estos etíopes para hacer las copas ebúrneas que se llenarán de vino. Vino producido en abundancia como para que los fenicios puedan llevarse una parte a cambio de las mercancías dejadas. Se presenta así un intercambio absolutamente coherente en el contexto de una elaboración mitológica.

Ni griegos ni fenicios comparten la mesa con etíopes e Inmortales en el relato homérico ni en el del Pseudo Escílax, lo que confiere un status privilegiado a estos particulares etíopes "sagrados", asimilados implícitamente por el autor ateniense a los atlantes al resaltar su gran talla. Estos constituyen el testimonio de un régimen antiguo ya periclitado en el que dioses y hombres llegaban a compartir la mesa, pues según Hesíodo, "Otrora comunes los festines eran, y comunes las asambleas para inmortales dioses y para mortales hombres". ${ }^{82}$

La presencia de los emporoi fenicios en estas latitudes sería secular ya que la tradición de los banquetes occidentales de los dioses se habría inaugurado en un remoto pasado. La asistencia comercial de los fenicios en esa época no parecería incongruente, ya que las redes fenicias de intercambios relacionadas con el mundo griego se consideraban en los textos homéricos plenamente consolidadas en la época de los héroes de la guerra troyana. ${ }^{83}$ Incluso un personaje como Menelao habría llegado en su periplo para acumular riquezas a las costas de los etíopes después de haber entrado en contacto con los fenicios. ${ }^{84}$ Pero seguramente el papel jugado por los fenicios como proveedores de los etíopes no se explica simplemente por su conocida frecuentación de estas costas y su valoración genérica como mercaderes, sino que, dado que estos etíopes aparecen regularmente caracterizados en las fuentes como nada hospitalarios

\footnotetext{
80 Hom. Il. XXIII, 205-207.

81 Hom. Od. I, 22-26.

82 fr. 1, Pap. Oxir. 2354.

83 Hom. Il. XXIII, 740-749; Od. XIV, 287-298.

84 Hom. Od. IV, 82.
} 
con otros humanos, ${ }^{85}$ reservando la hospitalidad a los dioses, parece más pertinente relacionar la admisión de los emporoi fenicios por parte de los etíopes con la necesidad de proveerse de los recipientes que les traen y por el hecho de que el Dionisos acogido por ellos se encontraba emparentado con los tirios, pues Semele, su madre, era nieta del rey de Tiro. ${ }^{86}$

\section{Comercio "no presencial"}

Un escueto texto de Heródoto ${ }^{87}$ se refiere a una práctica comercial realizada por los cartagineses con indígenas en un lugar indeterminado de la costa atlántica africana. Aunque éste se ha denominado tradicionalmente "comercio silencioso", convendría tipificarlo como "no presencial" ya que éste se realiza entre dos partes que nunca están presentes a la vez ante las mercancías que se van a intercambiar. Los productos eran depositados por los púnicos en la playa y una vez que éstos se habían retirado a su nave, se acercaban los indígenas para valorar las mercancías y depositar ante ellas cantidades de oro que eran retiradas después por los comerciantes semitas si las consideraban suficientes. En caso contrario volvían de nuevo a la embarcación a la espera de que añadieran más oro por las mercancías que les interesaban. Heródoto destaca la formación del justiprecio mediante este peculiar regateo y la ecuanimidad de la transacción, pues los indígenas no recogían los objetos hasta que los mercaderes hubieran tomado el oro.

Este mecanismo comercial se conoce aún en la Edad Media y en época moderna en el Sahel, referido precisamente al comercio del oro y también se daba entre algunos pueblos africanos que entraban en contacto para intercambiar alimentos. El trueque no presencial aparece frecuentemente como sustitutivo del mercadeo regular y amistoso cuando los vínculos y relaciones que se establecen con estas prácticas son difíciles de mantener, o son perniciosos o no deseables, normalmente por haber superado recientemente algún conflicto bélico o por una situación de enemistad endémica entre comunidades. La constitución de "mercados no presenciales" viene así determinada por el deseo de obtener las mercancías que les proveen los otros y el rechazo absoluto del contacto con los portadores de dichos bienes. Estas parecen ser las razones de más peso para el recurso a este mecanismo, y en conclusión hay que descartar que se trate de una forma básica o simple de trueque para considerarlo mejor como una forma anómala frente a los sistemas presenciales, que parecen mucho más extendidos. ${ }^{88}$

La información que Heródoto recogió de los cartagineses apunta precisamente hacia la idea de que alguna de las partes, si no las dos, quería evitar a toda costa dicho contacto. La razón podría ser un conflicto reciente habido con los Nigrites y Pharusii,

\footnotetext{
85 Hano 7.

86 Otros elementos de carácter semítico que requieren un desarrollo más amplio permiten considerar que se trata de una elaboración mitológica en parte compartida entre helenos y fenicios.

87 Hdt. IV, 196.

88 López PARdo 2001, 218-219.
} 
que acabó con numerosas colonias tirias destruidas. ${ }^{89}$ Pero también es posible que los etíopes, que no ofrecían hospitalidad ni a los lixitas ni a los cartagineses de Hannón, ${ }^{90}$ reservaran todas sus atenciones a los dioses que regularmente se reunían con ellos (dentro de una concepción eminentemente mitológica). Se puede establecer así una relación estrecha entre el "comercio no presencial", la tradición homérica del agasajo a las deidades olímpicas y la provisión fenicia de los utensilios para los banquetes etíopes mencionada por el Pseudo Escílax.

En suma, la impresión es que la codificación mítica de este confín de la tierra se fue construyendo desde sus inicios con connotaciones empóricas, las cuales no cesaron de caracterizar a estas tierras oceánicas, ricas en recursos escasos que los fenicios se empeñaron en obtener.

\section{Bibliografía}

Akerraz, A. - El Khayari, A. (2000): "Prospections archéologiques dans la région de Lixus. Résultats préliminaires", Africa Romana 13, Sasari, 1646-1668.

Amadasi Guzzo, M. G. (1992): "Notes sur les graffitis de Mogador", [en] Lixus, Actes du colloque, Roma, 155-157.

Aranegui, C. (ED.), (2001): Lixus. Colonia fenicia y ciudad púnico-mauritana, anotaciones sobre su ocupación medieval (Saguntum. Extra 4), Valencia.

Aranegui, C. - Belén, M. - Fernandez Miranda, M. - Hernández, E. (1992): “La recherche archéologique espagnole à Lixus: bilan et perspectives", [en] Lixus, Actes du colloque, Roma, 7-15.

Aranegui, C. - Gómez Bellard, C. - Jodin, A. (2000): "Los fenicios en el Atlántico. Perspectivas de nuevas excavaciones en Marruecos", Revista de Arqueología 223, 26-35.

Aranegui, C. - Kbiri Alaoui, M. - Vives-Ferrandiz Sánchez, J. (2004): “Alfares y producciones cerámicas en Mauritania occidental. Balance y perspectivas", [en] Figlinae Baeticae: talleres alfareros y producciones cerámicas en la Bética romana (ss. II a.C.-VII d.C.), Cádiz, 363-378.

Aranegui, C., et alii (2000): "Lixus. Arquitectura, cerámica y monedas de época púnico-mauritana", Revista de Arqueología 228, 14-24.

Ballouche, A. (1986): Paléoenvironnements de l'homme fossile holocène au Maroc. Apport de la palynologie, Thèse de doctorat dactylographié, Bordeaux I.

Blázquez y Delgado-Aguilera, A. (1921): "Las costas de Marruecos en la Antigüedad", Boletín de la Real Academia de la Historia 79, 400-418 y 481-509.

Boube, J. (1981): "Les origines phéniciennes de Sala de Mauretanie", Bulletin Archéologique du Comité des Travaux Historiques 17 b, 155-170.

89 Str. XVII, 3 y 8.

90 Hano 7. 
Bresson, A. (1993): "Les cités grecques et leurs emporia", [en] A. Bresson - P. Rouillard (eds.), L'Emporion, Paris, 163-226.

Carcopino, J. (1948): "Du Périple d'Hannon aux portulans grecs du XVI ${ }^{\mathrm{e}}$ siècle", Revue Archeologique 29-30, 132-141.

CinTAS, P. (1954): Contribution a l'étude de l'expansion carthaginoise au Maroc, Paris.

Cohen, D. (1999): Dictionnaire des racines sémitiques ou attestées dans les langues sémitiques, Paris-Leuven.

Desanges, J. (1978): Recherches sur l'activité des Méditerranéens aux confins de l'Afrique (Vie siècle avant J.C.-IVe siècle après J.C.), Roma.

Despois, J. - Raynal, R. (1967): Geographie de l'Afrique du Nord Ouest, Paris.

Euzennat, M. (1994): “Le Périple d'Hannon”, Comptes Rendus de l'Académie des Inscriptions et Belles-Lettres, 559-580.

FanTAR, M. H. (2002): "Matériaux phénico-puniques dans la version grecque du Périple d'Hannon", [en] M. Khanoussi - P. Ruggeri - C. Vismara (eds.), L'Africa Romana XIV (1), Roma, 75-82.

HABIBI, M. (1992): "La céramique phénicienne à vernis rouge de Lixus", [en] Lixus, Actes du colloque, Roma, 145-153.

Hamilton, R. (1992): Choes \& Anthesteria. Athenian Iconography and Ritual, Michigan.

Hoftizzer, J. - Jongeling, K. (1995): Dictionary of the North-West Semitic Inscriptions, Leiden.

JoDIN, A.

(1957): "Note préliminaire sur l'établissement pré-romain de Mogador", Bulletin d'Archéologie Marocaine 2, 9-40.

(1964): "Les gravures rupestres du Yagour (Aut-Atlas): Analyse stylistique et thématique", Bulletin d'Archéologie Marocaine 5, 47-116.

(1966): Mogador, Comptoir phénicien du Maroc atlantique, Rabat.

KBIRI Alaoui, M.

(2000): "A propos de la chronologie de la nécropole rurale d'Aïn Dalia Lekbira (région de Tanger, Maroc)", [en] Actas del IV Congreso Internacional de Estudios Fenicios y Púnicos, Cádiz, 1185-1196.

(2003): Comercio e intercambio en el Atlántico. Producciones e importaciones cerámicas del asentamiento fenicio-púnico y púnico-mauritano de Kuass (Asilah, Marruecos), Tesis doctoral, UCM.

Kbiri Alaoui, M. - López Pardo, F. (1998): "La factoría fenicia de Mogador (Essaouira, Marruecos): Las cerámicas pintadas", AEspA 71, 5-25.

Krahmalkov, C.R. (2000): Phoenician-Punic Dictionary (=Studia Phoenicia 15. Orientalia Lovaniensia Analecta 90), Leuven.

Le Glay, M. (1992): "Dchar Djedid”, [en] E. Lipinski (ed.), Dictionnaire de la Civilisation Phénicienne et Punique, Bruxelles, 127. 
LIPINSKI, E.

(1992): “L'aménagement des villes dans la terminologie phénico-punique”, L’Africa romana $X$, Oristano, 121-133.

(1992a): "Spartel, Cap", [en] E. Lipinski (ed.), Dictionnaire de la Civilisation Phénicienne et Punique, Bruxelles, 421-422.

(1992b): "Solo", [en] E. Lipinski (ed.), Dictionnaire de la Civilisation Phénicienne et Punique, Bruxelles, 420.

(1992c): "Sala", [en] E. Lipinski (ed.), Dictionnaire de la Civilisation Phénicienne et Punique, Bruxelles, 385.

(2000): "Vestiges puniques chez al-Bakrî", [en] M. Khanoussi - P. Ruggeri -- C. Vismara (eds.), L’Africa Romana XIII (1), Roma, 283-287.

LóPEZ PARDO, F.

(1990): "Nota sobre las ánforas II y III de Kuass (Marruecos)", Antiquités Africaines 26, 13-23.

(1992): "Reflexiones sobre el origen de Lixus y su Delubrum Herculis en el contexto de la empresa comercial fenicia", [en] Lixus, Actes du colloque, Roma, 85-101. (2000): El empeño de Heracles. La exploración del Atlántico en la Antigüedad, Madrid.

(2000a): "La fundación de Lixus", [en] Actas del IV Congreso Internacional de Estudios Fenicios y Púnicos, Cádiz, 819-826.

(2001): "Del mercado invisible (comercio silencioso) a las factorías-fortaleza púnicas en la costa atlántica africana", [en] P. Fernández Uriel - C. González Wagner - F. López Pardo (eds.), Intercambio y comercio preclásico en el Mediterráneo, I Congreso Internacional del Centro de Estudios Fenicios y Púnicos, Madrid, 216234.

(2005): "Una inscripción fenicia arcaica en el área de los templos de Lixus", $M a$ drider Mitteilungen 46, 46-60.

(2007): "Dioses en los prados del confín de la tierra: Un monumento cultual con betilos de Lixus y el Jardín de las Hespérides", Byrsa 3, 303-350.

López Pardo, F. - HabiBI, M. (2001): "Le comptoir phénicien de Mogador: Approche chronologique et céramique à engobe rouge", [en] Actes des lères Journées Nationales d'Archéologie et du Patrimoine, Rabat, 53-63.

López Pardo, F. - Mederos, A. - Ruiz Cabrero, L. A. (2006): "Sistemas defensivos en la toponimia fenicia de la costa atlántica", [en] Las ciudades fenicio-púnicas en el Mediterráneo Occidental, Almería, 384-403.

López PARdo, F. - SuÁrez, J. (2002): “Traslados de población entre el Norte de África y el sur de la Península Ibérica en los contextos coloniales fenicio y púnico", Gerión 20/1, 113-152.

LuQueT, A.

(1956): "Prospection punique de la côte atlantique du Maroc", Hesperis-Tamuda, $1^{\mathrm{o}}$ y $2^{\circ}$ trimestre, $117-132$.

(1973-1975): “Contribution a l'Atlas archéologique du Maroc. Le Maroc punique”, Bulletin d'Archéologie Marocaine 9, 261-270. 
Maniatis, Y., et alii (1985): "Punic Amphoras Found at Corinth, Greece: an Investigation of Their Origin and Technology", Journal of Field Archaeology 11, 205-222.

Mazard, J. (1955): Corpus numorum Numidiae Mauretaniaeque, Paris.

Olmo Lete, G. DEL

(1981): Mitos y leyendas de Canaán según la tradición de Ugarit, Valencia.

(1996): Diccionario de la lengua ugarítica (=Aula Orientalis-Supplementa), Sabadell.

Ponsich, M.

(1964): "Contribution a l'Atlas archéologique du Maroc: région de Tanger", Bulletin d'Archéologie Marocaine 5, 253-290.

(1966): "Contribution a l'Atlas archéologique du Maroc: région de Lixus", Bulletin d'Archéologie Marocaine 6, 377-422.

(1967): Nécropoles phéniciennes de la région de Tanger, Tanger.

(1968): Alfarerías de época fenicia y púnico-mauritana en Kuass (Arcila, Marruecos), Valencia.

(1970): Recherches archéologiques à Tanger et dans sa région, Paris.

(1981): Lixus. Le quartier des temples, Rabat.

(1982): “Territoires utiles du Maroc punique", [en] Phönizier im Westen, Mainz, 429444.

REBUFFAT, R.

(1970): Thamusida: Fouilles des Services des Antiquités du Maroc 2, Paris.

(1974): "Vestiges antiques sur la côte occidentale de l'Afrique au Sud de Rabat", Antiquités Africaines 8, 25-49.

(1976): "D'un portulan grec du XVIe siècle au Périple d'Hannon", Karthago 17, 139-151.

Ruhlman, A. (1939): "Le tumulus de Sidi Slimane (Rharb)", Bulletin de la Societé Préhistorique du Maroc 12, 47-64.

Ruiz Cabrero, L. A - López Pardo, F. (1996): "Cerámicas fenicias con graffiti de la isla de Essaouira (antigua Mogador, Marruecos)”, Rivista di Studi Fenici 24, 153-179.

Ruiz Mata, D. (1999): "La fundación de Gadir y El Castillo de Doña Blanca: contrastación textual y arqueológica", Complutum 10, 279-317.

Simoneau, A. (1968-1972): "Nouvelles recherches sur les gravures rupestres du Aut-Atlas et du Draa", Bulletin d'Archéologie Marocaine 8, 15-33.

Stumme, F. (1912): "Gedanken über libysch-phönizische Anklänge", Zeitschrift für Assyriologie 27, 121-128.

VERNET, R. (1996): “Un exemple de corrélation entre char et métal dans l'art rupestre mauritanien", [en] G. Aumassip, La préhistoire de l'Afrique de l'Ouest, Saint Maur, 69-73.

VILLARD, F. (1960): “Céramique grecque du Maroc", Bulletin d'Archéologie Marocaine 4, 1-26. 